\title{
Identification of corner separation modelling in axial compressor stage
}

\author{
Sergey A. Serkov ${ }^{1}$, Viacheslav A. Sedunin ${ }^{1}$, Vitalii L. Blinov ${ }^{1, *}$, Oleg V. Komarov ${ }^{1}$, and Yurii M. Brodov ${ }^{1}$ \\ ${ }^{1}$ Ural Federal University, Turbines and Engines Department, 620002 Yekaterinburg, Russia
}

\begin{abstract}
The paper presents a study of corner separations in hub to blade region at various operation conditions towards compressor stall. It is known that for compressor flows with low or none separations computation fluid dynamics with RANS methods work quite well, however, for highly separated flows they are no longer entirely valid. Therefore, several criteria were applied for prediction and quantification of possible corner separation, and the main interest of this work is in predicting the separation just before it will actually happen by certain flow metrics, so these metrics can be further used as a 'pre-stall' criteria whilst the RANS CFD operating point still behave within its appropriate limits. Also the effect of shear lean is discussed in the presented context.
\end{abstract}

\section{Introduction}

The main requirements for all gas turbine engines, regardless of their purpose, are high efficiency, operational reliability and long life span $[1,2]$. One of the key factors determining the efficiency of a gas turbine engine is the performance of an axial compressor and turbine. Since the flow in axial turbomachines is generally three-dimensional, it is important to consider a appropriate flow operating point in the blade channels [3].

A common phenomenon that becomes more significant as the pressure ratio of the compressor increases is the corner separation of the flow [4-7]. It occurs in the area of transition of the end-wall into the airfoil, leading to blockage of the flow path and decrease in the stall margin. In order to reduce the size of the corner separation, it is possible to perform aerodynamic optimization of the blade profile using a shear lean [612]. This method allows to increase the stall margin by reducing the pressure gradients and increasing the magnitude of the surface shear on the blades near the endwall.

In the frontal stages of the compressors, the effect of corner separation is comparatively less than in the rear stages, while the thickness of the endwall boundary layer is $1-2 \%$ of the height of the blade channel, which does not introduce significant changes in the flow structure, and the deviation of the actual velocity triangles from the calculated ones is insignificant [8]. As the flow moves to the intermediate and rear stages, a substantial increase in the endwall boundary layer occurs, which is associated with an increase in the incidence angle on the blades near the meridional contours. Moreover, the blockage due to this boundary layer can reach $20 \%$ of the span height [8].

\section{Materials and methods}

The flow in the blade channels was studied on a twostage low-speed axial compressor $[13,14]$, for which the CFD operating point was verified $[15,16]$. Understanding of the corner separation and its effect on the flow structure is important for optimization of the blade row, including an operating point where the optimization to be performed. For this purpose, certain criteria for identifying corner separation both near the endwall and in the blade channel have been proposed.

To select an operating point for optimization, it is necessary to establish how the corner separation of the flow develops in the blade channel and by what criteria it can be identified. At the same time, it is necessary to establish a threshold value of the criteria for the identification of the vortex, at which the corner separation will affect not only the region at the endwall, but also propagate towards the midspan, and also at what size of the corner separation it is possible to optimize the blade for reducing the size of this corner separation.

The determination of the critical size of the corner separation of the flow allows us to identify the operating point at which the optimization should take place. With an acceptable level of flow separation, the blade row works with high efficiency and productivity to ensure the required characteristics. With increasing aerodynamic load (1), the corner separation increases, which leads to a local decrease in the performance of blade sections and, as a result, their approach to their stall boundary. That is, optimization will be held at the conditions with sufficient incidence to cause the corner separation, but with no separation over the entire span of the blade.

\footnotetext{
* Corresponding author: v.l.blinov@urfu.ru
} 


$$
\psi=\frac{H_{a d}}{U^{2}}
$$

where $\mathrm{H}_{\mathrm{ad}}$ - adiabatic work; $\mathrm{U}$ - circumferential speed.

The separation point of the boundary layer on the blade surface is characterized by zero values of shear stresses on the wall $-\tau$ (Figure 1) $[4,17]$. At the pressure side of the blade, separation of the flow is unlikely and therefore, along the entire length of the flat section at any height of the blade, the shear stresses are above zero. Taking into account the condition for the onset of flow separation and the condition for the distribution of shear stresses on the pressure side, it is possible to obtain criterion (2), which characterizes the beginning of separation on the 2D section of the blade from its stall.

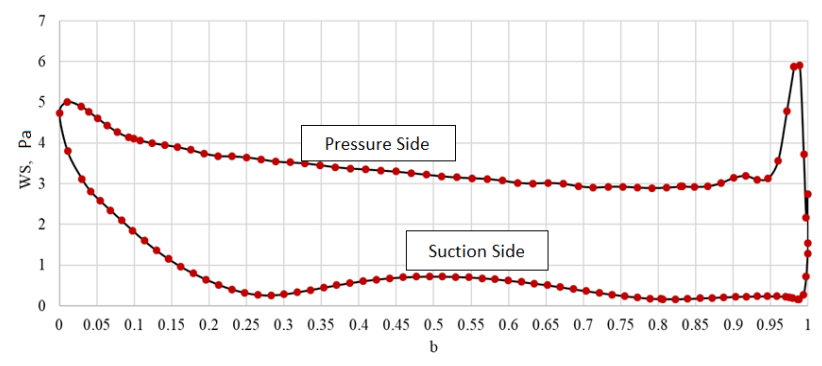

Fig. 1. Shear stress distribution $(\tau)$ along the profile chord.

The ratio of the shear stresses between the suction and the pressure sides will be a dimensionless parameter characterizing the separation of the flow regardless of the thermodynamic and kinematic quantities distributed along the chord of the blade.

$$
W S_{a}=\frac{\int_{0}^{1} \tau_{p s} \frac{d b}{b},}{\int_{0}^{1} \tau_{s s} \frac{d b}{b}}
$$

where $b$ is the blade chord; $\tau_{\mathrm{ss}^{-}}$shear stresses on the suction surface; $\tau_{\mathrm{ps}}$ - shear stresses on the pressure surface.

Since the blade is a set of flat sections, the analysis of the operation of only a separate $2 \mathrm{D}$ section does not make sense due to the three-dimensional nature of the flow. Therefore, to control the parameter $\mathrm{WS}_{\mathrm{a}}$ along the height of the channel, the blade is divided into 4 regions (Figure 2). This is done for the convenience of determining the response of the blade row performance to its geometric change. Regions 1 and 4 relate to areas at meridional contours from 0 to $20 \%$ and from 80 to $100 \%$, respectively. It is in these parts of the blade that the corner separation and tip vortex are formed. Flat sections located in these regions are the first to approach the boundary of their stability. Regions № 2 and 3 show the row performance at the middle part of the channel from 20 to $80 \%$ of the blade height. These regions are less loaded during compressor normal operation with minimum flow separation. Each area is responsible for monitoring the aerodynamic parameters of the flow and signals an increase or decrease in the loading, as well as change in the level of flow separation from the suction side [18].

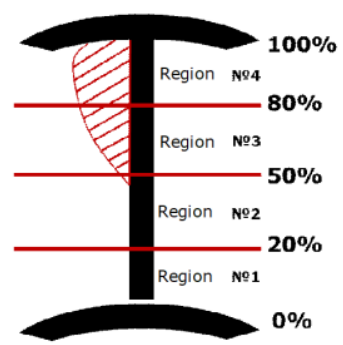

Fig. 2. Blade regions for WSa calculation.

\section{Results}

The study of the proposed criterion $\mathrm{WS}_{\mathrm{a}}$ was performed on the stator blades of the first stage of a low-speed twostage axial compressor at the entire operating range. The dependence of the parameter $\mathrm{WS}_{\mathrm{a}}$ on the diffusion factor (3) for each selected area was drawn (Figure 3).

$$
F_{d}=\left(1-\frac{C_{2}}{C_{1}}\right)+\left(\frac{C_{u 1}-C_{u 2}}{2 C_{1}}\right) \frac{t}{b},
$$

where $\mathrm{C}_{1}$ is the flow inlet velocity; $\mathrm{C}_{2}$ - flow outlet velocity; $\mathrm{C}_{\mathrm{u} 1}$ - circumferential projection of the flow velocity at the inlet; $\mathrm{C}_{\mathrm{u} 2}$ - circumferential projection of the flow velocity at the exit; $t / b$ - reversed solidity.

When loading rises, incidence, and, therefore, diffusion go up as well. That lead $\mathrm{WS}_{\mathrm{a}}$ to grow with distinctive parabolic lines.

Recommended values of the diffusion factor for stable operation vary in a range $\mathrm{Fd}=0.4 \ldots 0.6[19,20]$. In this case, in the guide vane of the first stage, the parameter $\mathrm{Fd}$ at the operating point is in the range from 0.1 to 0.2 , and when the recommended value $\mathrm{Fd}=0.4$ is reached, a corner separation is formed near the shroud, which extends to region 3 and 4 (Figure 3 ).

It is worth noting that with a small size of the corner separation, which extends only along the endwall and does not occupy a large area of the channel, the massaverage value in each particular section may be lower than the real value at the endwall.

At the operating point WSa is less than one, which can be explained by positive incidence. At a given incidence angle, shear stresses on the pressure side become lower than the ones at the suction side, but they are non-zero.

As the load increases, the ratio of shear stresses goes up. The highest sensitivity to the flow separation happens, when $\mathrm{WS}_{\mathrm{a}}$ reaches 1.6..1.8. Further compressor operation will be accompanied with a developed corner separation next to endwalls, which extends beyond the 20 percent zone. Optimization of the blade row below the critical values of $1.6 \ldots 1.8$ will be impractical, since the flow is less affected by separation, or the separation does not create sufficient blockage of the channel.

An analysis of streamlines showed that when the row works at the value of $\mathrm{WS}_{\mathrm{a}}=1.6 \ldots 1.8$, corner separation propagates along the blade only in region 4 , and there are no saddle points on the suction surface, the presence of which would indicate the presence of vortex motion 


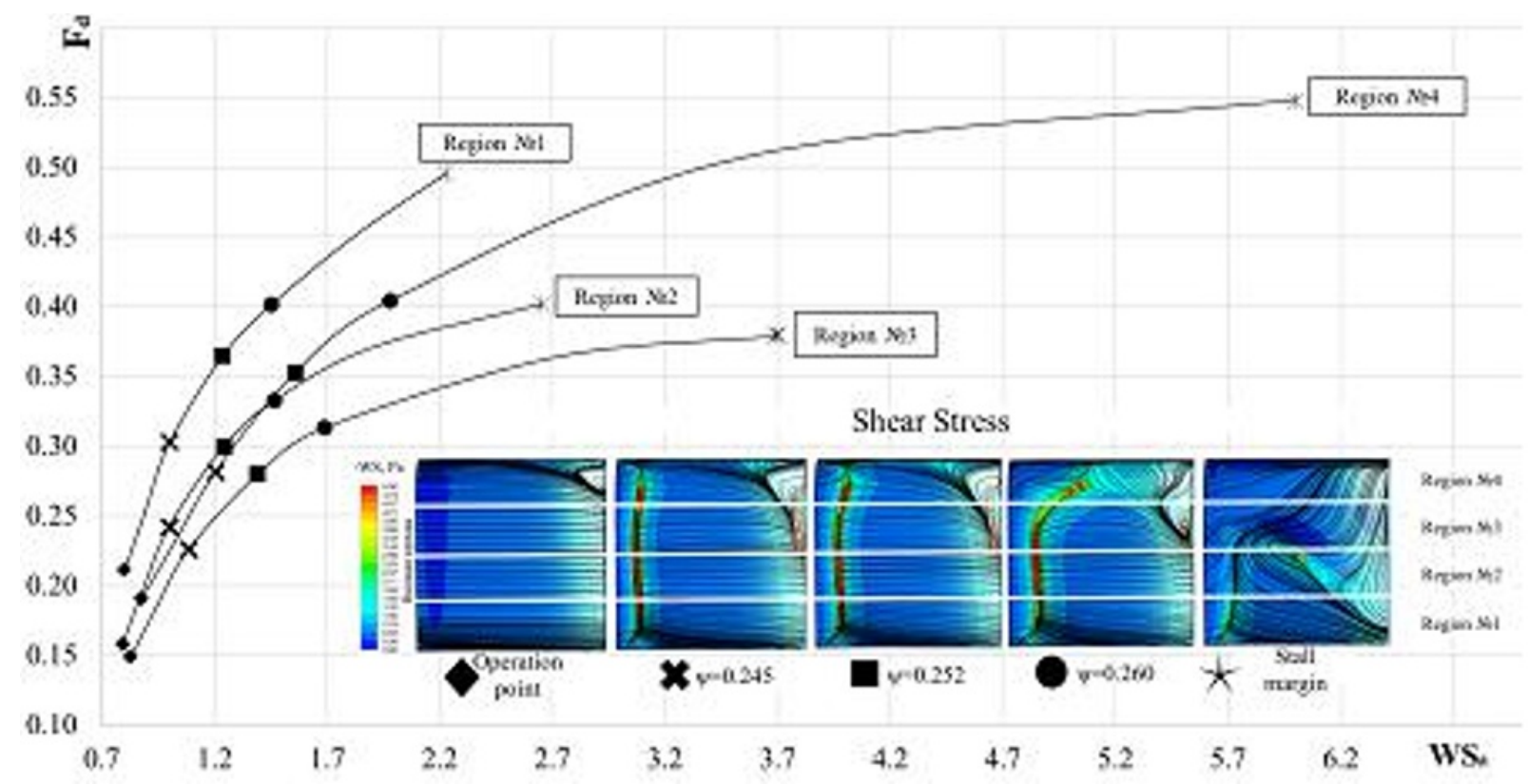

Fig. 3. $\mathrm{WS}_{\mathrm{a}}$ parameter vs diffusion factor.

(Figure 3). With a further increase in aerodynamic loading, the corner separation extends to region 3, which increases the value of $\mathrm{WS}_{\mathrm{a}}$ to values $1.6 \ldots 1.8$ in zone 4 , and a saddle point is formed on the surface of the blade along with focal points and nodal lines, which indicates the formation of a vortex along the blade. Therefore, when the corner separation is propagated along the blade, its transition from the region near the meridional contour to the region of the middle of the blade determines the threshold value for the beginning of the corner separation formation as $\mathrm{WS}_{\mathrm{a}}=1.6 \ldots 1.8$ regardless of the flow in the channel, since the parameter $\mathrm{WS}_{\mathrm{a}}$ is a dimensionless quantity and depends only on local parameters on the blade surface.

It is not possible to predict the separation of the flow using only direct physical quantities, such as velocity and pressure, since the separation of the flow depends on the derivatives of these quantities. Whereas, using the $\mathrm{WS}_{\mathrm{a}}$ criterion, flow separation is determined by reducing the strength of interaction between the flow and the surface of the blade, which, in turn, depends on a decrease in the gradient of the flow velocity normal to the surface $(\mathrm{du} / \mathrm{dy})$ and dynamic flow viscosity $(\mu)(4)$.

$$
\tau=\mu \frac{d U}{d y},
$$

The $\mathrm{WS}_{\mathrm{a}}$ criterion shows only the presence of the flow separation from the wall at which the action propagates only at the surface of the blade. At the same time, calculations of channel blockage using direct physical quantities only allows us to calculate the region where the flow velocity is less than the freestream one, and separation has already happened. However, adjacent to the separation zone there is a bigger region with significantly higher turbulence intensity. This larger zone can be taken into account when predicting the operation of the row and determining the operating point for row optimization.
To determine the dimensions of the flow separation and the blockage area of the channel, a second criterion is proposed, which includes the ratio of the area that is determined in the region of the turbulence intensity above $\mathrm{TI}=30 \%$ (5) to the cross-sectional area of the channel (F) (Figure 4, left) (6).

The turbulent flow rate is defined as:

$$
T I=\frac{\sqrt{\frac{2}{3} E_{k}}}{V} 100 \%,
$$

where $E_{k}$ is the kinetic energy of the flow; $V$ is flow velocity.

$$
T I_{a}=\frac{\left(F-T I_{\text {area }}\right)}{F} 100 \%
$$

The largest area of the corner separation region is expected at the trailing edge, that explains the choice of identification plane (Figure 4, left). To set a threshold value for turbulence intensity, the criterion for the area of flow turbulence intensity was limited to $30 \%$. The streamlines that are detached from the surface of the blade at the interface between the vortex and the free steady flow zone have a high turbulence intensity, which is about $30 \%$ (Figure 4 , right).

The vortex forming the corner separation has high turbulence intensity and includes not only the region of flow separation itself, but also the vortex formation region limited by the limiting current line, and the area corresponding to $\mathrm{TI}_{\mathrm{a}}=30 \%$ will be larger than the area with low Mach numbers of the corresponding average values within the separation region.

Comparison of the blockage area with isosurfaces of low Mach number (Ma) and the $\mathrm{TI}_{\mathrm{a}}$ criterion (Figure 5) shows that near design operating points, the isosurface blockage area based on $\mathrm{TI}_{\mathrm{a}}$ criterion is higher than blockage area based on Mach number. Further raise in 

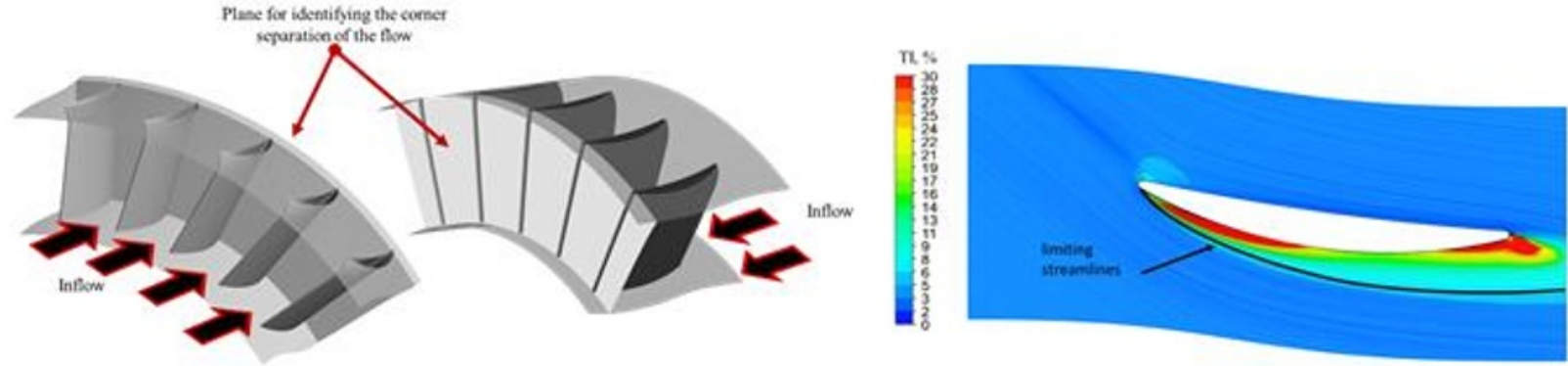

Fig. 4. Surface location for corner separation identification (left) and Turbulence intensity for limiting streamlines (right).
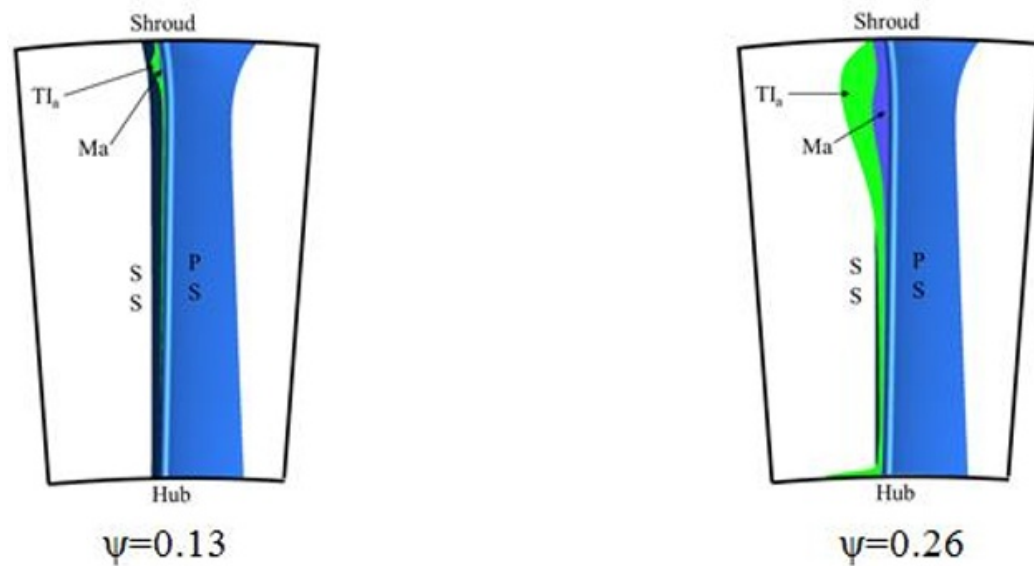

Fig. 5. Blockage area with Mach number and TIa parameter.

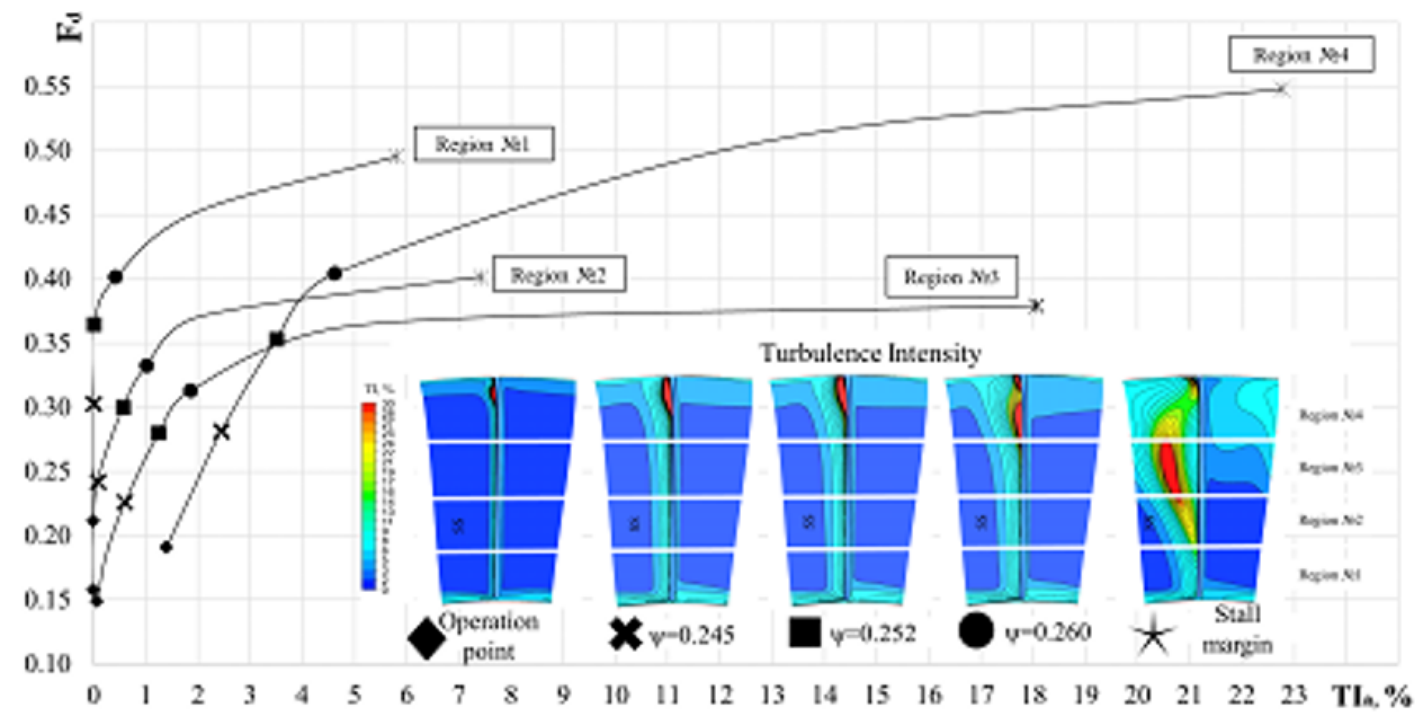

Fig. 6. Parameter $\mathrm{TI}_{\mathrm{a}}$ vs diffusion factor for stator 1 .

loading causes the $\mathrm{TI}_{\mathrm{a}}$ parameter to reach $7 \%$, which is 3.5 times greater than the Mach number based blockage.

Thus, this parameter allows you to identify the corner flow separation at the point when the flow separation based on the Mach number does not pose a danger to the stable operation of the row. This makes it possible to predict the behaviour of the row at higher loading, which, in turn, allows you to estimate the stall margin.

As well as the $\mathrm{WS}_{\mathrm{a}}$ criterion, the $\mathrm{TI}_{\mathrm{a}}$ criterion is related to the diffusion factor (Figure 6). In this case, at the $4^{\text {th }}$ region of Stator 1, flow separation exists at the operating point and the blockage is $1.5 \%$ based the TIa criterion. Further loading increase leads to greater channel blockage and when the value $\mathrm{TI}_{\mathrm{a}}=4 \ldots 7 \%$ is reached at the shroud, the graph becomes rather horizontal.

Therefore, when the $\mathrm{TI}_{\mathrm{a}}$ value reaches critical values of $4 \ldots 7 \%$, it shows that the corner separation passes from the near-endwall region towards the midspan.

\section{Discussion}

Based on the distribution of the parameters $\mathrm{TI}_{\mathrm{a}}$ and $\mathrm{WS}_{\mathrm{a}}$ in stator blade row, a diagram was obtained for determining the row operating points depending on the 


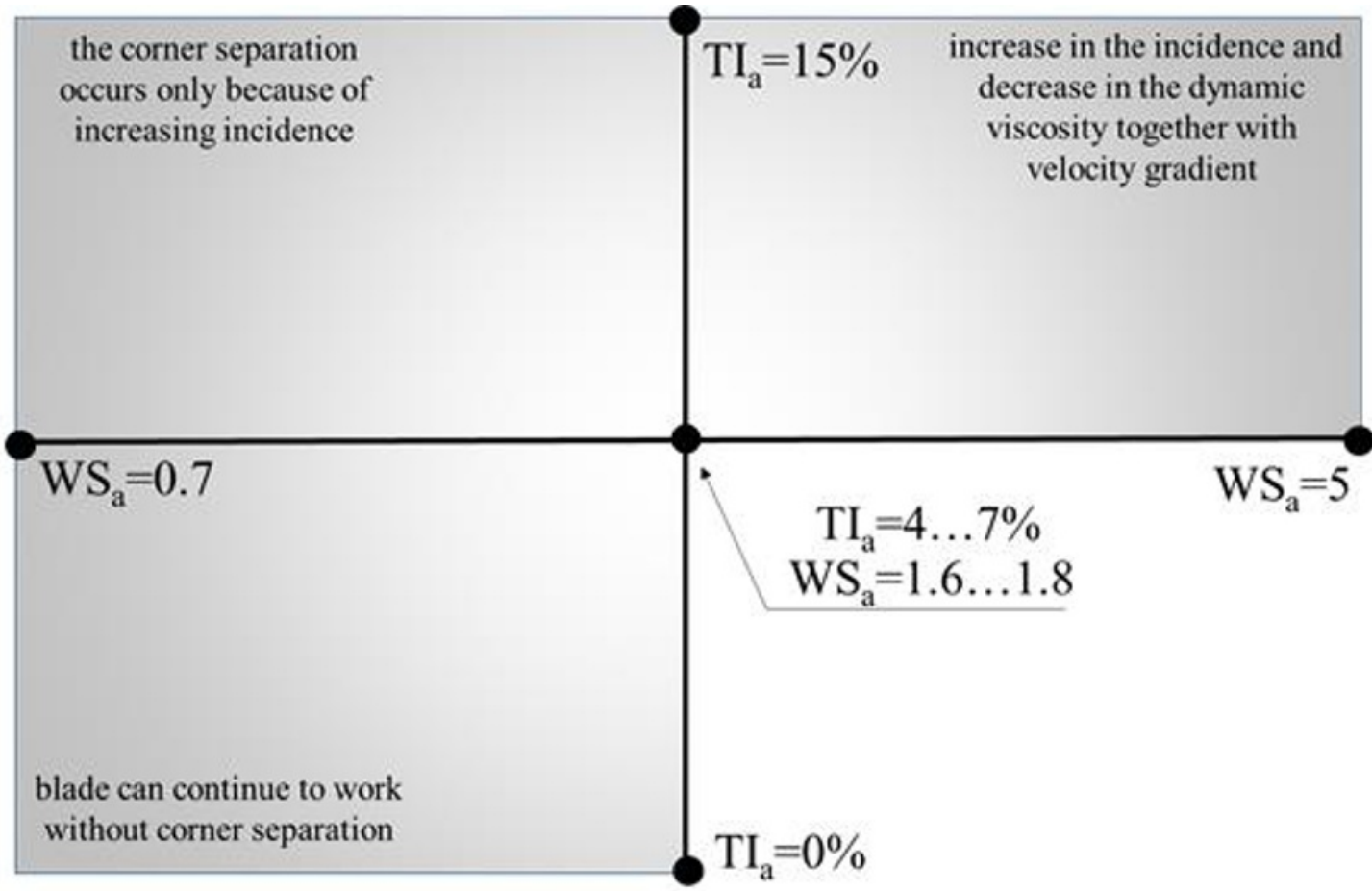

Fig. 7. The degree of corner separation development the blade channel, depending on the values of $\mathrm{TI}_{\mathrm{a}}$ and $\mathrm{WS}_{\mathrm{a}}$.

degree of development of the corner separation (Figure 7). Based on this diagram, it is possible to determine how critical the analysed operating point for the compressor performance.

If the values of the parameter $\mathrm{TI}_{\mathrm{a}}$ at the exit from approach $4 . .7 \%$, but the values of the parameter $\mathrm{WS}_{\mathrm{a}}$ are closer to 1, then the corner separation occurs only because of increasing incidence. In this case, the flow in the suction side boundary layer has the necessary velocity gradient normal to the surface, and the flow viscosity is sufficient so as not to form a swirl region along the profile surface.

Increase in both $\mathrm{TI}_{\mathrm{a}}$ and $\mathrm{WS}_{\mathrm{a}}$ means simultaneous increase in the incidence and decrease in the dynamic viscosity together with velocity gradient. Thus, the separation of the flow begins at the leading edge and continues along the entire suction surface of the selected area. In this case, saddle and focal points are formed on the surface, which signal a vortex motion near the wall.

\section{Conclusions}

It is established that the criteria $\mathrm{WS}_{\mathrm{a}}$ is used to identify the corner separation at the blade surface, and the criterion TIa is used to determine the spanwise extension of the corner separation. At the same time, they may not necessarily be optimised at the same compressor operating point due to the different nature of the flow in the rows and the different shape of the blade.

First of all, it is necessary to evaluate the effect of corner separation on the flow in the channel using the $\mathrm{TI}_{\mathrm{a}}$, and additionally check the $\mathrm{WS}_{\mathrm{a}}$. This is because first the blockage of the channel will be determined, which affects the performance of the compressor, and then the degree of resilience to separation of each zone using the
$\mathrm{WS}_{\mathrm{a}}$ will be determined. If the threshold value is reached for any isolated distinguished zone for the $\mathrm{TI}_{\mathrm{a}}$ (the threshold value of blockage is reached), but the ratio of the shear stresses of the suction and pressure side is below the limit $\mathrm{WS}_{\mathrm{a}}=1.6 \ldots 1.8$, (streamlines that separate from the blade do not form vortex between the limiting streamlines and the blade surface) it is possible to optimize the selected blade row, but this region of the blade can continue to work with corner separation.

The results obtained can be used in 3D optimization of compressor blade rows by means of lean, sweep and dihedral

\section{References}

[1] N.A. Cumpsty, Compressor aerodynamics (Longman Scientific \& Technical, 1989)

[2] V.A. Sedunin, O.V. Komarov, Blinov V.L., A.V. Skorokhodov, S.A. Serkov, Yu.M. Brodov, Redesign of an axial compressor with mass flow reduction of $30 \%$, Third International Conference on Energy Production and Management in the 21st Century 222, 93-101 (2018)

[3] V.A. Sedunin, O.V. Komarov, V.L. Blinov, A.V. Skorokhodov, A.O. Procopets, The application of modern computational fluid dynamics techniques for increasing the efficiency and stability of an axial compressor in an industrial gas turbine, Energy Production and Management in the 21st Century 190, 707-719 (2014)

[4] U. Dallmann, Topological Structures of Threedimensional Flow Separation (DFVLR, Gottingen, 26-45, 1983) 
[5] H. To, R. J. Miller, The effect of aspect ratio on compressor performance, Proceedings of ASME Turbo Expo, GT2015-43016 (2015)

[6] J.D. Denton, L. Xu, The effects of lean and sweep on transonic fan performance, ASME Turbo Expo, GT-2002-30327 (2002)

[7] S.J. Gallimore, J.J. Bolger, N.A. Cumpsty, M.J. Taylor, P.I. Wright, and J.M. Place, The use of sweep and dihedral in multistage axial flow compressor blading - part 1: university research and methods development, Journal of Turbomachinery 124, 521-532 (2002)

[8] R.F. Behlke, The Development of a Second Generation of Controlled Diffusion Airfoils for Multistage Compressors, Journal of Turbomachinery 108 (1986)

[9] M.Yu. SHelkovskij, Aerodinamicheskoe sovershenstvovanie osevogo desyatistupenchatogo kompressora stacionarnogo GTD, Aviacionno-kosmicheskaya tekhnika i tekhnologiya 9, 27-32 (2014)

[10] Jr.R.W. Moore, D.L. Richardson, A study of the end wall boundary layer in an axial compressor blade row, Massachusetts Institute of Technology Report (1955)

[11] O.V. Komarov, V.A. Sedunin, V.L. Blinov, Application of optimisation techniques for new high-turning axial compressor profile topology design, Proceedings of ASME Turbo Expo, GT2014-25379 (2014)

[12] V.L. Blinov, V.A. Sedunin, O.V. Komarov, Multi-criteria optimisation of subsonic axial compressor blading, IOP Conf. Series: Materials Science and Engineering, 643 (2019)

[13] M.D. Hathaway, Axial compressoriishi Aerodynamic design and performance of a twostage, axial-flow compressor (baseline), Asmes84178, TCRL-24 (1983)

[14] D.L. Tweedt, T.H. Axial compressoriishi Stator blade row geometry modification influence on two-stage, axial-flow compressor aerodynamic performance, Asmes-84179 TCRL-25 (1983)

[15] O.V. Komarov, V.A. Sedunin, V.L. Blinov, S.A. Serkov, Verifikaciya zadachi chislennogo modelirovaniya techeniya vozduha $\mathrm{V}$ osevoj kompressornoj stupeni, Vestnik Moskovskogo gosudarstvennogo tekhnicheskogo universiteta im. N.E. Baumana. Seriya «Mashinostroenie 4, 54-68 (2016)

[16] Yu.M. Brodov, O.V. Komarov, V.A. Sedunin, V.L. Blinov, S.A. Serkov, Osobennosti verifikacii CFD-modeli osevogo kompressora. CHast' 2: analiz integral'nyh parametrov, Kompressornaya tekhnika i pnevmatika, 4 (2018)

[17] D.J. Peake, M. Tobak, Three-Dimensional Interactions and Vortical Flows with Emphasis on High Speeds, Agardograph, 252 (1980)
[18] S.A. Serkov, Identifikaciya i ustranenie uglovogo otryva potoka $v$ lopatochnyh vencah pri reshenii zadach chislennogo modelirovaniya techeniya $v$ osevyh kompressorah GTD ( Ekaterinburg, UrFU, 2019)

[19] A.R. Howell, Design of axial compressors, Proceedings of the Institute Mechanical Engineers (1945)

[20] Yu.B. Galerkin, L.I. Kozachenko, Turbokompressory: ucheb. posobie (SPb.: Izd-vo Politekhn. un-ta, 2008) 